\title{
EDITORIAL
}

\section{Respiratory rehabilitation: improvement of short- and long-term outcome}

\author{
R. Gosselink
}

Studies over the last 5-10 yrs have clearly demonstrated the benefits of rehabilitation programmes on chronic obstructive pulmonary disease (COPD) patients' exercise capacity, quality of life, and utilisation of healthcare resources. Despite these achievements, several unanswered questions need to be addressed to further improve the outcome of rehabilitation in COPD. The effects of exercise training on survival, the effectiveness of various modalities of exercise training and the maintenance of the effects in the long-term remain largely unknown. In the current issue of the European Respiratory Journal, the latter two of these issues are addressed. VoGIATzIS et al. [1] report on the feasibility of interval training as an alternative training modality for endurance training. Indeed, most training programmes in COPD rehabilitation are based on endurance training, which effectively means periods of sustained exercise for 20-30 min. High-intensity training is needed for an improvement in exercise performance [2], but severely obstructed patients with hypoxaemia and hypercapnia or patients with severe muscle weakness, poorly tolerate such high intensities for longer periods of time [3]. Central restraints in addition to peripheral skeletal-muscle dysfunction might hamper endurance exercise training in these cases [4]. During interval training, short periods ( $30 \mathrm{~s}-2 \mathrm{~min}$ ) of high-intensity exercise will stress the working muscle mass without being limited by central restraints evoking too many symptoms. The paper by Vogiatzis et al. [1] demonstrates that interval training induces similar improvements in exercise performance and quality of life in comparison to endurance training. Importantly, symptoms of dyspnoea during the exercise sessions were significantly lower in the interval-training group. This might also improve compliance with exercise training programmes and thus, the effectiveness of this treatment. This study suggests that patients with more severely impaired physiological capabilities should be considered eligible for rehabilitation. However, only moderate physiological training effects, i.e. maximum oxygen consumption $\left(V^{\prime} \mathrm{O}_{2} \max \right)$ did not

Respiratory Rehabilitation and Respiratory Division and Faculty of Physical Education and Physiotherapy, University Hospitals, Katholieke Universiteit Leuven, Leuven, Belgium.

Correspondence: R. Gosselink, Respiratory Rehabilitation and Respiratory Division and Faculty of Physical Education and Physiotherapy, University Hospitals, Katholieke Universiteit Leuven, Leuven B-3000, Belgium. Fax: 32 16346866. E-mail: rik.gosselink@uz.kuleuven.ac.be improve in either group, were demonstrated. This was probably due to the low training frequency of only twice a week. This is below the threshold to observe clear physiological training responses, as indicated in the recommendations of the American College of Sports Medicine [5].

BROOKS et al. [6] dealt with the issue of long-term maintenance of the improvements after rehabilitation. It is well known that training effects are reversed in the long-term when exercise training is stopped [5]. This is true for healthy subjects and is also demonstrated in patients with COPD [7]. BRoOKs et al. [6] observed no effects in two different follow-up programmes after a 6-8-weeks rehabilitation programme. A monthly session with supervised exercise was not different from a follow-up interview at 3-monthly intervals. Both follow-up programmes were unable to prevent a clear reduction over $1 \mathrm{yr}$ in exercise performance and quality of life. The study's other important finding was that $>50 \%$ of the patients did not complete the follow-up period. In addition, $80 \%$ of the patients identified an exacerbation as the main reason for noncompliance with prescribed home exercises. It seems difficult to keep up with practicing exercise training without supervision especially after exacerbations. Rehabilitation programmes should develop strategies to minimise the risk for relapse and thus, inactivity due to exacerbations. Patients should be taught how to prevent becoming inactive again after an exacerbation. The best way to develop such a strategy is probably by experiencing the recovery from an exacerbation during the rehabilitation programme. Since an average of 2.4 exacerbations per year were reported for COPD patients [8], longer lasting rehabilitation programmes will allow most patients to face exacerbations during the programme. Teaching these patients how to recover from the exacerbation with exercise training will probably improve long-term outcome. Indeed, Troosters et al. [9] observed long-lasting effects after 6 months of rehabilitation, without any formal follow-up programme. Like other rehabilitation programmes, the programme by BROOKs et al. [6] had a relatively short duration (6-8 weeks) and most patients probably did not face an exacerbation during the rehabilitation period. The potential effect of the duration of the programme on longterm outcome is another important variable to be considered in further optimising rehabilitation programmes. 


\section{References}

1. Vogiatzis I, Nanas S, Roussos C. Interval training as an alternative modality to continuous exercise in patients with COPD. Eur Respir J 2002; 20: 12-19.

2. Casaburi R, Patessio A, Ioli F, Zanaboni S, Donner CF, Wasserman K. 1. Reductions in exercise lactic acidosis and ventilation as a result of exercise training in patients with obstructive lung disease. Am Rev Respir Dis 1991; 143: 9-18.

3. Maltais F, Leblanc P, Jobin $\mathrm{J}$, et al. Intensity of training and physiologic adaptation in patients with chronic obstructive pulmonary disease. Am J Respir Crit Care Med 1997; 155: 555-561.

4. Richardson RS, Sheldon J, Poole DC, Hopkins SR, Ries AL, Wagner PD. Evidence of skeletal muscle metabolic reserve during whole body exercise in patients with chronic obstructive pulmonary disease. Am J Respir Crit Care Med 1999; 159: 881-885.

5. American College of Sports Medicine. Position stand. The recommended quantity and quality of exercise for developing and maintaining cardiorespiratory and muscular fitness, and flexibility in healthy adults. Med Sci Sports Exerc 1998; 30: 975-991.

6. Brooks D, Krip B, Mangovski-Alzamora S, Goldstein RS. The effect of postrehabilitation programmes among individuals with chronic obstructive pulmonary disease. Eur Respir $J$ 2002; 20: 20-29.

7. Ries AL, Kaplan RM, Limberg TM, Prewitt LM. Effects of pulmonary rehabilitation on physiologic and psychosocial outcomes in patients with chronic obstructive pulmonary disease. Ann Intern Med 1995; 122: 823-832.

8. Seamungal TAR, Donaldson GC, Paul EA, Bestall JC, Jeffries DJ, Wedzicha JA. Effect of exacerbation on quality of life in patients with chronic obstructive pulmonary disease. Am J Respir Crit Care Med 1998; 57: $1418-1422$.

9. Troosters T, Gosselink R, Decramer M. Short and long-term effects of outpatient pulmonary rehabilitation in COPD patients, a randomized controlled trial. Am J Med 2000; 109: 207-212. 